Research Article

\title{
Analysis of castor bean ribosome-inactivating proteins and their gene expression during seed development
}

Guilherme Loss-Morais ${ }^{1}$, Andreia Carina Turchetto-Zolet ${ }^{2}$, Matheus Etges ${ }^{1}$, Alexandro Cagliari ${ }^{2}$, Ana Paula Körbes ${ }^{2}$, Felipe dos Santos Maraschin ${ }^{3}$, Márcia Margis-Pinheiro ${ }^{2}$ and Rogério Margis ${ }^{1,4}$

${ }^{1}$ Centro de Biotecnologia, Universidade Federal do Rio Grande do Sul, Porto Alegre, RS, Brazil.

${ }^{2}$ Departamento de Genética, Universidade Federal do Rio Grande do Sul, Porto Alegre, RS, Brazil.

${ }^{3}$ Departamento de Botânica, Universidade Federal do Rio Grande do Sul, Porto Alegre, RS, Brazil.

${ }^{4}$ Departamento de Biofísica, Universidade Federal do Rio Grande do Sul, Porto Alegre, RS, Brazil.

\begin{abstract}
Ribosome-inactivating proteins (RIPs) are enzymes that inhibit protein synthesis after depurination of a specific adenine in rRNA. The RIP family members are classified as type I RIPs that contain an RNA-N-glycosidase domain and type II RIPs that contain a lectin domain (B chain) in addition to the glycosidase domain (A chain). In this work, we identified 30 new plant RIPs and characterized 18 Ricinus communis RIPs. Phylogenetic and functional divergence analyses indicated that the emergence of type I and II RIPs probably occurred before the monocot/eudicot split. We also report the expression profiles of 18 castor bean genes, including those for ricin and agglutinin, in five seed stages as assessed by quantitative PCR. Ricin and agglutinin were the most expressed RIPs in developing seeds although eight other RIPs were also expressed. All of the RIP genes were most highly expressed in the stages in which the endosperm was fully expanded. Although the reason for the large expansion of RIP genes in castor beans remains to be established, the differential expression patterns of the type I and type II members reinforce the existence of biological functions other than defense against predators and herbivory.
\end{abstract}

Keywords: agglutinin, evolution, lipase, Ricinus communis, ricin, RIPs.

Received: May 17, 2012; Accepted: August 21, 2012.

\section{Introduction}

Ribosome-inactivating proteins (RIPs) are enzymes that irreversibly inhibit protein synthesis by cleaving the glycosidic bond between adenine and ribose in the exposed loop of $28 \mathrm{~S}$ rRNA that is involved in the interaction between rRNA and elongation factors 1 and 2, i.e., RIPs act as specific RNA- $N$-glycosidases (Endo and Tsurugi, 1987). This specific depurination of rRNA blocks the interaction between rRNA and elongation factors and interrupts protein synthesis (Endo et al., 1991).

RIPs are classified as type I RIPs that consist of a single polypeptide chain $(\sim 30 \mathrm{kDa})$ with RNA- $N$-glycosidase activity and correspond to the A chain, and type II RIPs that consist of a protein dimer containing an A chain and a B chain $(\sim 35 \mathrm{kDa})$ linked by disulfide bonds (Peumans et al., 2001; Stirpe, 2004). The B chain has lectin activity, recognizes terminal galactose residues and facilitates the interaction between type II RIPs and the cell membrane (Lord et al., 1994).

Send correspondence to Rogério Margis. Centro de Biotecnologia, Universidade Federal do Rio Grande do Sul, Avenida Bento Gonçalves 9500, Prédio 43431, Campus do Vale, Caixa Postal 15005, 91501-970 Porto Alegre, RS, Brazil. E-mail: rogerio.margis@ufrgs.br.
RIPs have been identified primarily in plants but have also been found in bacteria, algae and fungi (Girbes et al., 2004). The castor bean (Ricinus communis), an oil-rich crop (Scholz and da Silva, 2008), contains the proteins ricin and agglutinin, both of which are type II RIPs. Ricin is the best-characterized RIP of the group (Lord et al., 1994). The interest in ricin is related to its cytotoxicity towards mammalian cells (Spivak and Hendrickson, 2005), its potential use in biological weapons (Franz et al., 1997), its use as a research tool to study intracellular transport (Roberts and Smith, 2004) and its therapeutic uses against tumors (Schnell et al., 1996; Wang et al., 1998) and AIDS (Scadden et al., 1998; Donayre Torres et al., 2009).

Genomic and transcriptomic analyses of ricinencoding genes (Halling et al., 1985; Lamb et al., 1985) have shown that this protein is synthesized from a single mRNA that encodes a preproprotein known as preproricin, which contains the A and B chains. Preproricin contains 576 amino acids, the first 35 of which correspond to the signal peptide required for translocation of the protein to the endoplasmic reticulum (ER) lumen. The 267 residues beyond the signal peptide form the A chain which is linked to the 262 residues of the $B$ chain by a linker peptide of 12 residues (Lamb et al., 1985; Frigerio and Roberts, 1998). The 
linker peptide is a signal for vacuolar sorting (Frigerio et al., 2001). Once the protein is sorted into a vacuole the linker peptide is proteolytically removed to promote ricin activation (Frigerio et al., 1998).

Agglutinin shares high structural similarity with ricin (Roberts et al., 1985), which suggests that agglutinin may have evolved from duplication of the ricin gene (Ready et al., 1984). Agglutinin has strong agglutinating activity but low RIP activity (Hegde and Podder, 1998). Like ricin, agglutinin is expressed as a preproprotein, with the formation of a self-assembled tetramer determining its RIP and agglutinating activities (Roberts et al., 1985).

X-ray crystallography (Monzingo and Robertus, 1992) and site-directed mutagenesis (Kim et al., 1992) studies have identified the ricin residues that are critical for catalysis. The adenine of rRNA binds between two conserved tyrosine residues and the core active site is formed by two residues, a glutamic acid and an arginine (Day et al., 1996). More recently, a tryptophan residue located near the active site is apparently important for preservation of the active site structure (Ding et al., 2003). Site-directed mutagenesis, protein structural analyses and protein kinetics experiments have shown that, in addition to its RIP activity, ricin also has lipolytic activity that is targeted to glycerophospholipids and especially triglycerides (Morlon-Guyot et al., 2003). In this same study, the active site of ricin, which contains histidine, serine (A chain) and glutamic acid (B chain), was also characterized.

The paralogous ricin genes were first characterized by Southern blot analysis and six genes were proposed to be members of the ricin gene family (Halling et al., 1985). Later, the ricin agglutinin family was found to contain eight members (Tregear and Roberts, 1992). The recent publication of the castor bean draft genome revealed the presence of 28 putative RIP genes, including those for ricin, agglutinin and possibly pseudogenes (Chan et al., 2010). To date, six ricin-like castor bean proteins have been shown to contain RIP activity (Leshin et al., 2010).

To gain an overall picture of the R. communis RIP gene family, we have re-examined the 28 candidate castor bean RIP genes and the genome draft. Additional plant type I and type II RIPs were identified in addition to the foregoing ricin and agglutinin genes. The expression patterns of the castor bean RIP genes were analyzed by quantitative PCR at five stages of seed development. The phylogenetic relationship of these proteins with other plant RIPs and the functional divergence among type I and II castor bean RIPs are discussed.

\section{Materials and Methods}

\section{Plant material}

The inflorescences of mature AL-Guarany 2002 castor bean plants cultivated at EMBRAPA Clima Temperado (Pelotas, RS, Brazil) were collected for seed dissection.
Five seed developmental stages (S1 to S5) were selected based on morphological differences described in previous work (Chen et al., 2004) and in a recent publication by our group (Cagliari et al., 2010). Briefly, the first stage (S1) contains seeds $\sim 0.5 \mathrm{~cm}$ wide that are green-yellow and lack a testa (seed coat) and caruncle, stage S2 contains seeds $\sim 1$ $\mathrm{cm}$ wide that are light yellow and lack a testa and early caruncle, stage $\mathrm{S} 3$ contains seeds $\sim 1 \mathrm{~cm}$ wide that are yellow with dark spots and show early formation of the testa and the caruncle during maturation, stage $\mathrm{S} 4$ contains seeds with $\sim 1 \mathrm{~cm}$ wide that are dark brown and contain a formed testa and caruncle and stage S5 contains mature seeds.

\section{Identification of RIPs}

The castor bean ricin sequence (60629.m00002) was used as a query for BLAST searches against plants with sequenced genomes in the Phytozome database and against Jatropha curcas in the NCBI database. The 28 putative $R$. communis RIPs (Chan et al., 2010) and rice RIPs (Jiang et al., 2008) were retrieved from the Phytozome database by a keyword search. All of the sequences were screened using the InterProScan (Quevillon et al., 2005) tool and were inspected manually for the presence of RIP motifs. The FancyGene (Rambaldi and Ciccarelli, 2009) and WebLogo (Crooks et al., 2004) programs were used to illustrate the castor bean gene composition and amino acid conservation, respectively. The crystallographic model of ricin (pdb code 2AAI) was used with the software Swiss-Pdb-Viewer (version 4.0.1) (Guex and Peitsch, 1997) to illustrate the active site of the RIPs and their association with lipase activity.

\section{Phylogenetic analysis and functional divergence}

The retrieved RIP sequences were aligned using MUSCLE (Edgar, 2004) implemented in MEGA 5.0 (Tamura et al., 2011) and contained customized adjustments. The protein sequence alignments were used for the phylogenetic analyses that were done using the Bayesian and maximum-likelihood (ML) methods. The Bayesian analysis was done with MrBayes 3.1.2 (Ronquist and Huelsenbeck, 2003) using the mixed amino acid substitution model plus gamma and invariant sites. Two independent runs of $5,000,000$ generations each with a parallel Metropoliscoupled Markov chain Monte Carlo (MCMCMC) were run in parallel (each started from a random tree). The Markov chains were sampled every 100 generations and the first $25 \%$ of the trees were discarded as burn-in. The remaining generations were used to compute the majority rule consensus tree (Allcompat command in MrBayes), the posterior probability of the clades and the branch lengths. The convergence of the two runs was assessed by checking the average standard deviation of the split frequencies $(<0.01)$ and the potential scale reduction factor (PSRF, which was very close to 1.0 for all of the parameters). The maximum-likelihood (ML) method was run in PhyML 3.0 (Guindon et al., 2010) and the branch points were tested for 
their significance by bootstrapping with 100 replicates. The sequences that covered only the A chain domain were used to construct RIP trees. The phylogenetic trees were rooted with a medium point and visualized using FigTree software (http://tree.bio.ed.ac.uk/software/figtree/).

The functional divergence was estimated with DIVERGE 2.0 software (Gu and Vander Velden, 2002) which detects evolutionary functional divergence. This software used a phylogenetic tree to assess site-specific changes in the evolutionary rates within the amino acid alignments between the subgroups (type I and type II RIPs). The coefficient of evolutionary functional divergence $(\theta)$ was used to measure changes in the site-specific evolutionary rate. A value of $\theta=0$ indicated a lack of functional divergence, while increasing values of $\theta$ indicated increasing functional divergence, with $\theta=1$ being the maximum.

\section{RNA extraction, primer design and expression analysis by RT-qPCR}

Total RNA from the dissected seeds was extracted with NucleoSpin columns (Macherey-Nagel) and purified with an PolyATract mRNA isolation system III (Promega) according to the manufacturer's specifications for optimal mRNA isolation. Reverse transcription of the first strand of cDNA was done using $2 \mu \mathrm{g}$ of purified mRNA, the primer $\mathrm{T} 25 \mathrm{~V}(1 \mu \mathrm{g} / \mu \mathrm{L})$ and 200 units of M-MLV reverse tran- scriptase (Promega) in a final volume of $50 \mu \mathrm{L}$. The cDNA products were diluted $1: 10$ and stored at $-80^{\circ} \mathrm{C}$. The reverse transcriptase reaction was done as follows: a denaturation step of $5 \mathrm{~min}$ at $70^{\circ} \mathrm{C}$ was followed by a rapid thaw on ice and elongation at $42{ }^{\circ} \mathrm{C}$ for $1 \mathrm{~h}$. Genomic DNA from the S5 seed stage was extracted with a PureLink Total DNA purification kit (Invitrogen) according to the manufacturer's instructions.

Primer3 (Rozen and Skaletsky, 2000) was used to design the $R$. commnuis RIP-specific primer pairs (Table 1). All of the PCR amplification products were sequenced using an automatic sequencer (ABIPRISM 3100 Genetic Analyzer, Applied Biosystems) to confirm the identity of the $R$. commnuis RIP cDNAs and the specificity of the primers.

The gene expression patterns in the five stages of seed development were assessed by quantitative real-time PCR (RT-qPCR) that was done in a StepOnePlus real-time PCR system (Applied Biosystems) using SYBR green dye. Briefly, the cDNAs were diluted up to 100 -fold and mixed with primers $(0.2 \mu \mathrm{M})$, dNTPs $(25 \mu \mathrm{M}), 1 \mathrm{X}$ PCR reaction buffer (20 mM Tris- $\mathrm{HCl}$ and $50 \mathrm{mM} \mathrm{KCl}$ ), $3 \mathrm{mM} \mathrm{MgCl}_{2}$, $0.1 \mathrm{X}$ SYBR green, Platinum Taq polymerase $(0.25 \mathrm{U} / \mu \mathrm{L})$ and DNAse-free water in a total volume of $20 \mu \mathrm{L}$ per reaction tube. The RT-qPCR conditions were as follows: an initial hot-start step at $94{ }^{\circ} \mathrm{C}$ for 5 min was followed by 40 cycles of denaturation at $94{ }^{\circ} \mathrm{C}$ for $15 \mathrm{~s}$, annealing at

Table 1 - Ricinus communis ribosome-inactivating protein (RIP) access codes in the Phytozome database and the acronyms and primer sequences that were designed for RT-PCR and RT-qPCR.

\begin{tabular}{|c|c|c|c|c|}
\hline \multirow[t]{2}{*}{ Access code } & \multirow[t]{2}{*}{ Acronym } & \multicolumn{2}{|c|}{ Primer sequences } & \multirow[t]{2}{*}{ Amplicon size (bp) } \\
\hline & & Forward primer & Reverse primer & \\
\hline 29638.m000512 & Rco_I1 & TTAAGTATGCTTCCTCTCCTTCAACT & TGTCTGAATGGCAATGGAAA & 197 \\
\hline 29638.m000513 & Rco_I2 & AACCTATGATGGGACTCTTGCTT & TTGACAGCAGCTGGATGAAG & 93 \\
\hline 60638.m00022 & Rco_I3 & AATATATCGAGGAAAAATTGGTTGAG & TTGCAGATGTCTGAATTGCTTC & 117 \\
\hline 28842.m000952 & Rco_I4 & AGAGAATACCACATTGGGAACCTA & GCAGCCTCTGAAACCATTTG & 129 \\
\hline 29852.m001982 & Rco_I5 & GAGAGTACAACACTGGGAAGTGG & CAATTCTTGCTCGATATATGTGAATC & 156 \\
\hline 29942.m000748 & Rco_I6 & CCAAAACGAGGGGATTTGA & TGTGGCCAAGTACAGCAAGA & 183 \\
\hline 30113.m001449 & Rco_I7 & AATAGGATTGCAAGATGAAAACTACC & GCATTGGCAAGAACTTTTTGAT & 146 \\
\hline 60629.m00002 & Rco_Ric & GCGTATCGTAGGTCGAAATGG & GCGTTTCCGTTGTGAATC & 62 \\
\hline 60637.m00004 & Rco_Aggl & GAGCCCATAGTGCGTATCGTA & CTGTCCTGGACTGGACTTGG & 198 \\
\hline 60638.m00019 & Rco_II3 & TCACGGATGTTCCAAATCC & TAAAGCGCTGAGATAGCATCC & 130 \\
\hline $60638 . \mathrm{m} 00018$ & Rco_II4 & GTGCACGTCCACCATCAA & CATTTCGACCCGCGATAC & 114 \\
\hline 29988.m000128 & Rco_II5 & TTGTTTGCATCCAAATGGC & GCAGATCTTCGATTGTGTCG & 118 \\
\hline 29988.m000125 & Rco_II6 & TTCAACCACTTACGGGTACAA & TCTGGGATTTATGATGGTTCC & 92 \\
\hline 60638.m00023 & Rco_II7 & GCTCAAACAATACCCAACGG & AAAGCTCTGCCTGATTTGTGA & 200 \\
\hline 60637.m00006 & Rco_II8 & GGTCATTCACATTGCAGGATAGT & ACGTCATCTCCAGCTAATAATTGA & 145 \\
\hline 29791.m000533 & Rco_II9 & TCAACCAGCTTGGCGG & CTGTCACGCAGCACTGGTAT & 173 \\
\hline 29942.m000749 & Rco_II10 & GGATATGCTTTGGCAGCATC & TGCAGGACTGCAAGATGAAA & $312 *$ \\
\hline $60638 . \mathrm{m} 00025$ & Rco_II11 & GATACCATGCTTAAGCTCGAGAAG & TCCACTTTTTCTCCGCTCAC & 138 \\
\hline
\end{tabular}

*183 bp in genomic DNA. 
$60{ }^{\circ} \mathrm{C}$ for $10 \mathrm{~s}$, extension at $72{ }^{\circ} \mathrm{C}$ for $15 \mathrm{~s}$ and an additional step for the data recording at $60{ }^{\circ} \mathrm{C}$ for $35 \mathrm{~s}$; after the cycling stage, an additional melting curve was obtained with an initial step at $50^{\circ} \mathrm{C}$ for $120 \mathrm{~s}$ that was followed by a stepwise increase in temperature $\left(0.3{ }^{\circ} \mathrm{C} /\right.$ step $)$ up to $99^{\circ} \mathrm{C}$.

The previously described reference genes, i.e., elongation factor-B (29785.m000934), ubiquitin (30169.m006323) and the ubiquitin conjugation protein rad6 (29736.m002026) (Cagliari et al., 2010), were used to normalize the castor bean RIP expression levels by the $2^{-\Delta \Delta C t}$ method (Livak and Schmittgen, 2001). All experiments were done in quadruplicate.

\section{Results}

\section{Identification of RIP genes}

To identify new RIP-encoding genes in plants, BLAST and keyword searches were done in the Phytozome and NCBI databases. Eighty-four putative RIP sequences were retrieved (Supplementary material Table S1). The numbers of genes varied from one copy in Cucumis sativus (Csa) to 20 members in Oryza sativa (Osa). The $R$. communis (Rco) genome contained 18 RIP-encoding genes. Of the 84 RIPs, 30 have not previously been published, including genes from Manihot esculenta, Prunus persica, Cucumis sativus, Populus trichocarpa, Sorghum bicolor, Setaria italica, Brachypodium distachyon and Zea mays. Although Z. mays and S. bicolor also contained type II RIPs in their genomes, the canonical amino acids in the active site that were responsible for the toxic proprieties were replaced in these species (Table S1).

Alignment of the 18 castor bean sequences revealed the presence of 7 type I and 11 type II RIPs. In the present work, ricin and agglutinin were annotated as Rco_Ric and Rco_Aggl, respectively. The remaining $R$. communis RIPs were annotated and numbered according to their relative type. Figure 1 shows the detailed structure of the genes for the 18 R. communis RIPs, including the coding sequences, introns and linker peptide positions. Rco_II3, Rco_II5 and Rco_I4 contained a single intron each whereas Rco_II10 contained seven introns; all of the other members lacked introns. We used the linker peptide position to estimate the boundary of the A and B chains and to determine their relative lengths. The size of the A chains was more uniform when compared to that of the B chain counterparts. Rco_II3 and Rco II10 contained B chains that were half the size of the other $R$. communis type II RIPs.

One striking finding was that Rco_II5 and Rco_II11 showed no linker peptide while their B chain counterparts were classified as type II RIPs (Figure 1). Sequence analysis revealed that following the gene duplication that gave rise to Rco_II5, a guanine base was introduced into the sequence and resulted in a chain termination mutation that introduced a premature stop codon (Figure 2). The sequence alignment of Rco_II4 and Rco_II5 showed that the intro-

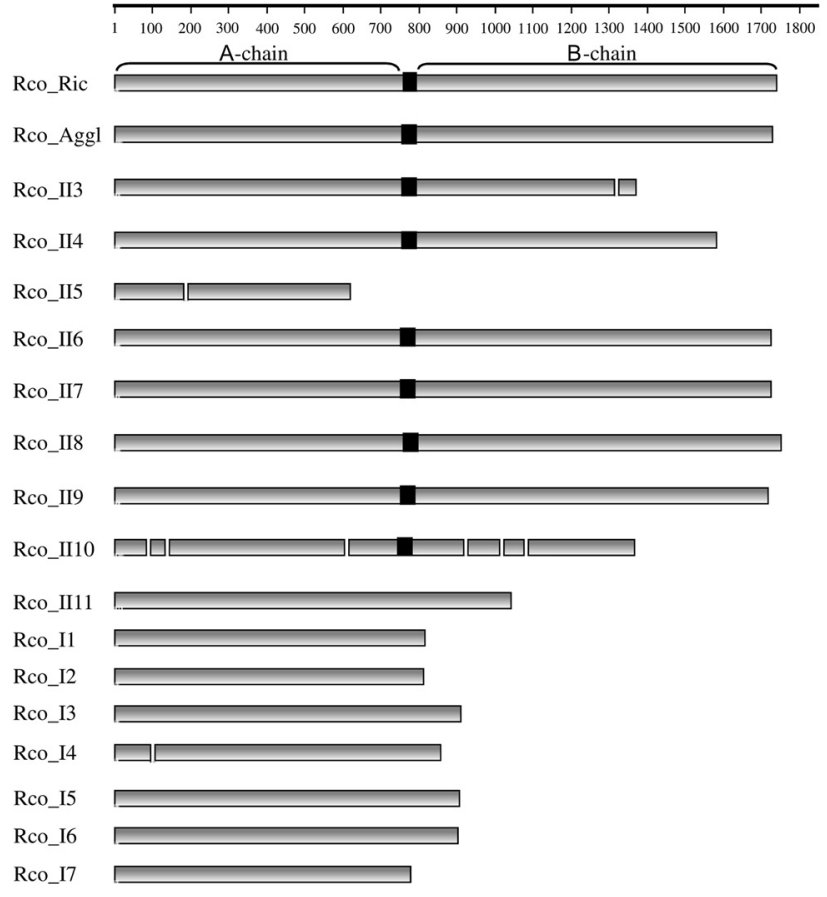

Figure 1 - Structure of the 18 R. communis RIP (Rco_RIP)-encoding genes. The exons are shown in grey boxes and the linker peptide regions that delimit the A and B chains are indicated by black boxes. The introns that were detected are shown out of scale by interruption of the grey boxes.

duced stop codon was present in a different frame in Rco_II4 (Figure 2). Indeed, the downstream Rco_II5 sequence, which is out of the translational frame, may be a portion of a non-functional A chain. In this case, the upstream 29988.t000011 gene (ricin-agglutinin family protein) was most likely a part of the Rco_II5 B chain and the current Rco_II5 sequence is a portion of a truncated A chain. The downstream sequence of Rco_II5 shared high nucleotide identity with the equivalent region of Rco_II4, which supports the finding that the Rco_II5 downstream region is a non-functional portion of Rco_II5 (Figure 2). However, Rco_II11 did not contain a linker peptide region and the 5-kbp downstream sequence of the Rco_II11 gene showed no similarities to or signatures of the B chain (data not shown).

The conservation of the amino acid sequences of $R$. communis RIPs was analyzed with the WebLogo tool. The residues in the active site cleft, which is responsible for the toxic properties of RIPs (Figures 3A,B), and the catalytic triad, which is responsible for the lipolytic activity (Figures 3A,C,D), showed high conservation. This conservation was maintained even among the A chains of type I and type II Rco RIPs (Figure 3A). These findings indicate that other plant species in addition to $R$. communis contain RIP genes. These findings indicate that despite the high diversity among $R$. communis RIP gene structures there is strong amino acid conservation among the proteins encoded by these genes. 


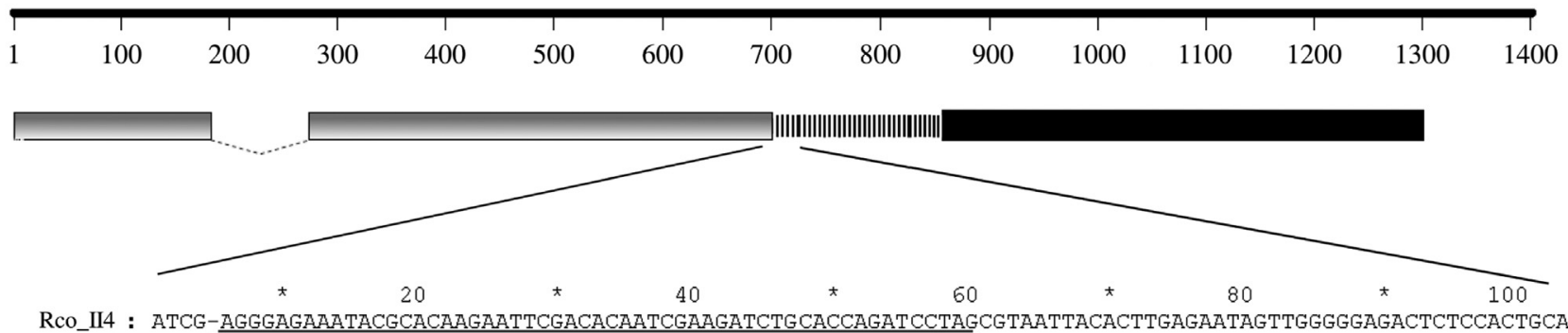

Rco_II5 : ATCGGAGGGAGAAATACGCACAAGAATCGACACAATCGAAGATCTGCACCAGATCCTAGcgtaattacacttga-aatagttaggggagactctcCactgca

Figure 2 - Structures of the 29852.t001982 (Rco_II5) and 29988.t000011 (ricin-agglutinin family protein) genes and the sequence alignment of Rco_II5 and Rco_II4. The Rco_II5 exons are shown in grey boxes and the introns are indicated by dashed lines. The intergenic regions are identified by the striped box and the 29988.t000011 gene is shown as a black box. The sequence alignment of Rco_II5 and Rco_II4 showed that a chain termination event caused by the addition of a guanine base (amino acid identified by grey shading) introduced a translational frame shift that resulted in a premature stop codon (amino acid identified by black shading) and occurred after the Rco_II5 and Rco_II4 duplication event. The intergenic region, indicated by lower-case letters, also demonstrates the high sequence identity of the Rco_II4-equivalent region.

Type I and II plant RIPs show independent parallel evolution

Bayesian and maximum likelihood (ML) trees were constructed based on the 84 RIP sequences that were retrieved (Figure 4 and Supplementary material Figure S1, respectively). The Bayesian and ML trees showed similar topologies and revealed evolutionary partitioning of the type I and II RIPs, which indicated that RIP clustering was based mostly on the protein type rather than the species of origin. The R. communis RIPs showed a clustering pattern in which type I RIPs were more closely related to other Euphorbiaceae type I RIPs than to type II RIPs. A similar patern of clustering was observed for Zma_II1, Sbi_II1 and type II $R$. communis RIPs (Figure 4 and Figure S1). The phylogenetic tree also showed that duplication events occurred independently in both of the $R$. communis type clades and that the internal duplication events were recent. The exceptions were Rco_II10 and Rco_II11, neither of which grouped with their corresponding clades (Figure 4 and Figure S1).

To complement the phylogenetic studies, the extent of functional divergence between the RIP genes was analyzed using the DIVERGE software. The coefficient of functional divergence theta $(\theta)$ represents the extent of divergence of a specific amino acid site between two protein groups, where $\theta=1$ represents the maximum divergence. The mean $\theta$ between $R$. communis type I and II RIPs and the $J$. curcas, M. esculenta and monocot type I RIPs was calculated (Figure 5) and the results confirmed the clustering pattern for the RIP types shown in Figure 4. The value of $\theta$ was always smaller when RIPs of the same type were compared, indicating that RIPs are more functionally divergent between types than within the same type (Figure 5). The phylogenetic and functional analyses indicated that RIPs of the same type were more evolutionarily related to each other and less functionally divergent than were RIPs of different types or clades.

\section{Rco_Ric and Rco_Aggl are the most highly expressed RIPs in seeds}

PCR using the genomic DNA of seeds was done to confirm the presence of the $R$. communis RIPs identified in silico in the castor bean genome. All 18 of the $R$. communis RIP amplicons produced PCR bands of the predicted size (Table 1 and Figure S2), thus confirming the existence of the $R$. communis RIP genes that had been retrieved from the Phytozome database. The identities of the PCR products from the $18 R$. communis RIPs were also confirmed by sequencing (data not shown).

The expression of these RIPs during seed development was initially assessed by RT-PCR using cDNA from mature seeds. In this seed stage, only Rco_Ric (ricin), Rco_Aggl (agglutinin) and Rco_II5 showed detectable amplicons, indicating that these RIPs were highly expressed in mature seeds (Figure S2). Because RT-PCR is not a sensitive method for the detection of low levels of gene expression, we also undertook accurate gene expression quantification analysis by RT-qPCR in five seed developmental stages.

These expression analyses revealed that $10 R$. communis RIP genes were expressed in developing seeds (Figure 6). Among the type I R. communis RIPs, Rco_I3, Rco_I4, Rco_I5 and Rco_I7 showed a similar pattern of expression, with the highest expression occurring in stages S3 and S4 (Figure 6A). The type II $R$. communis RIPs Rco_Ric, Rco_Aggl, Rco_II4, Rco_II5, Rco_II6 and Rco III1 also showed the highest expression in stages S3 and $\mathrm{S} 4$ (Figure 6B). Together these results indicate that the 18 R. communis RIPs that were identified in silico are present in the $R$. communis genome and that four type I and six type II RIP genes are expressed during seed development. 

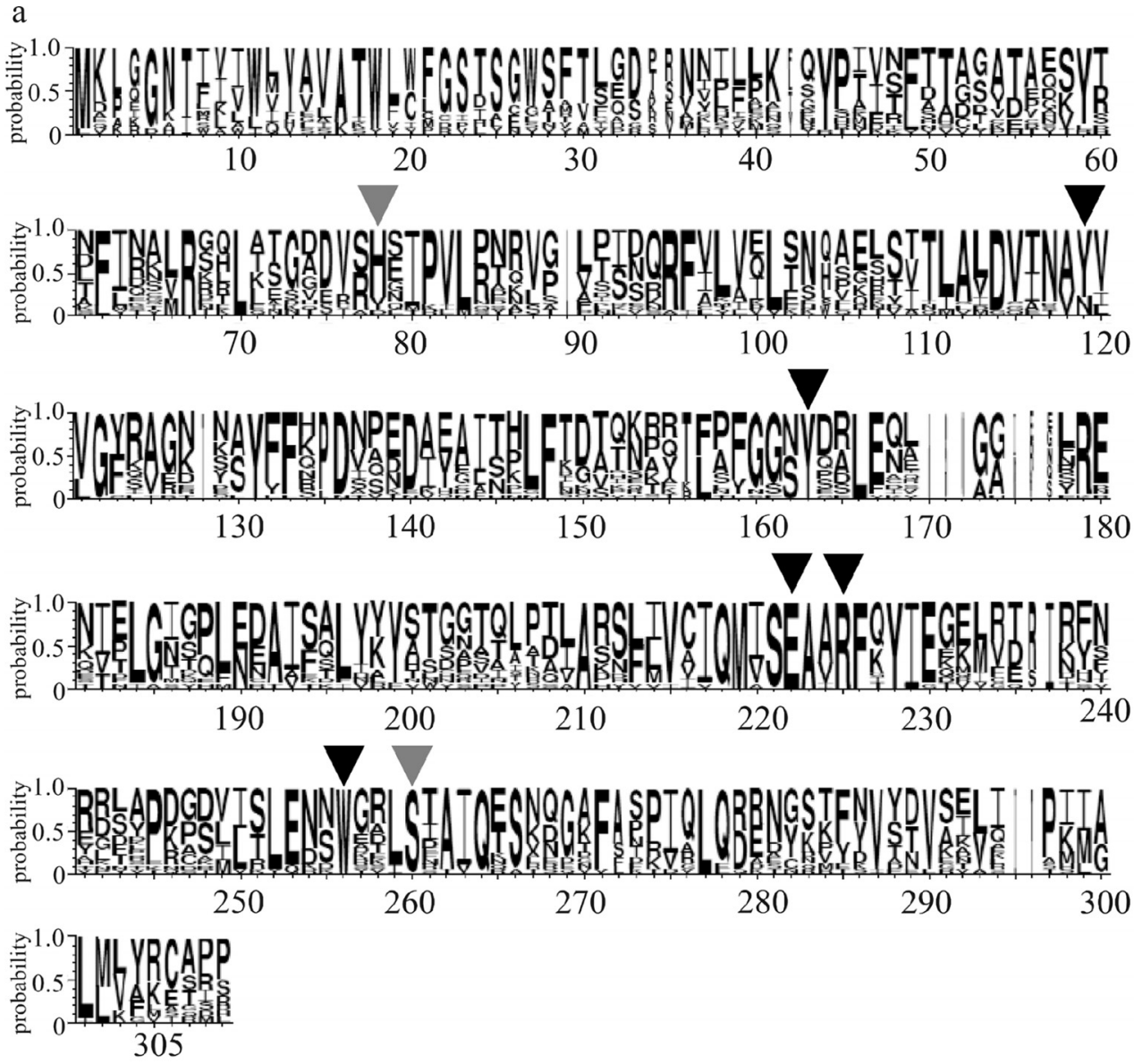

b
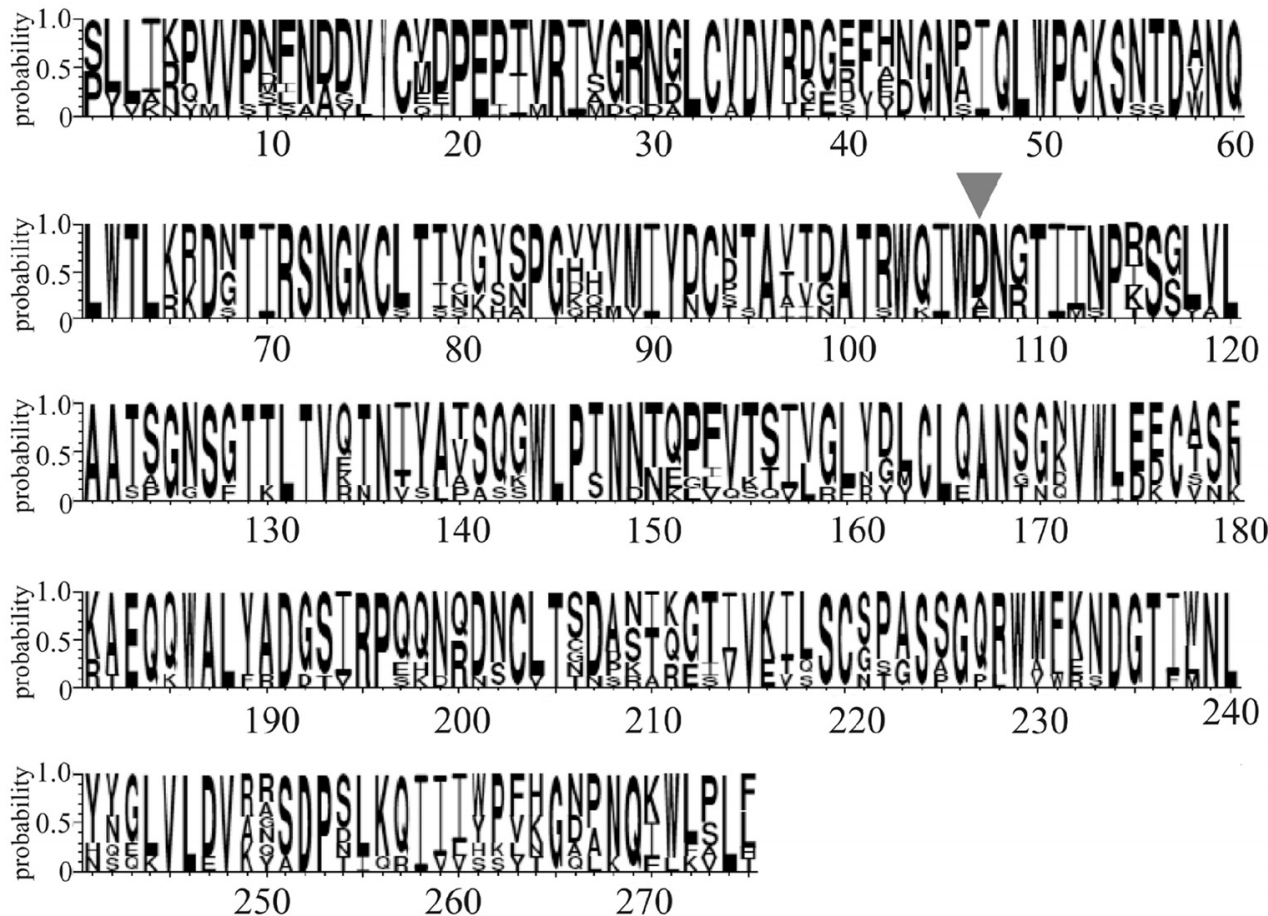

Figure 3 - Logo and crystallographic visualization of the A and B chains of $R$. communis RIPs. (a) Logo representation of all the $R$. communis A chains. (b) Logo representation of all the $R$. communis $\mathrm{B}$ chains. The logo heights in these graphs represent the amino acid probability for each position. The residues of the active site of Rco_Ric that are responsible for toxicity are indicated by the black arrowheads, and the active site residues that are responsible for the lipolytic activity are indicated by the grey arrowheads. 

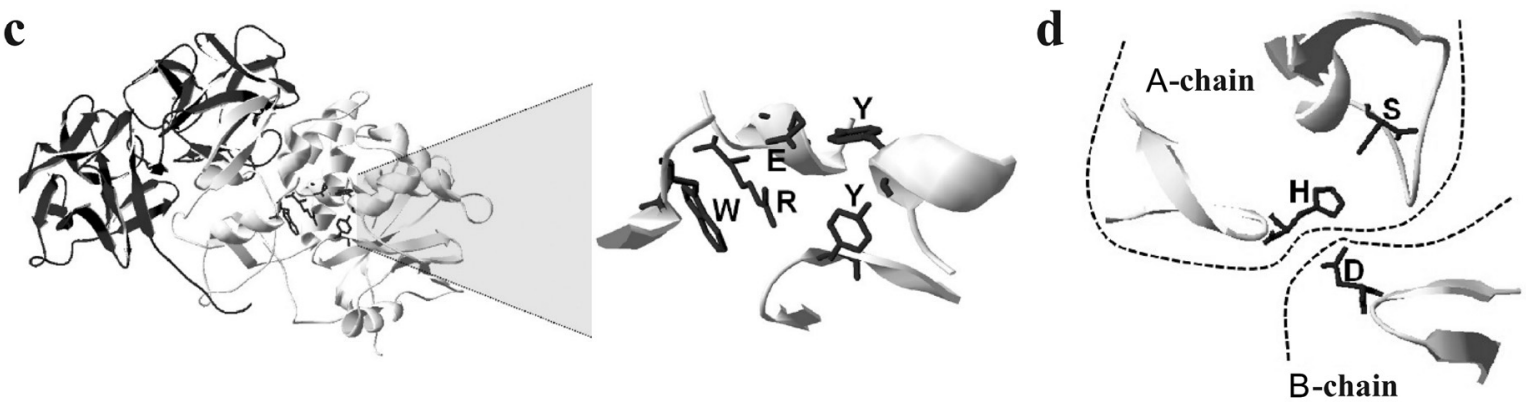

Figure 3 (cont.) - (c) A crystallographic model of ricin (pdb 2AAi) with the A chain in gray and the B chain in black. The spatial conformation of the active site responsible for toxicity is indicated. (d) Model representing the spatial conformation of the lipolytic active site of ricin.

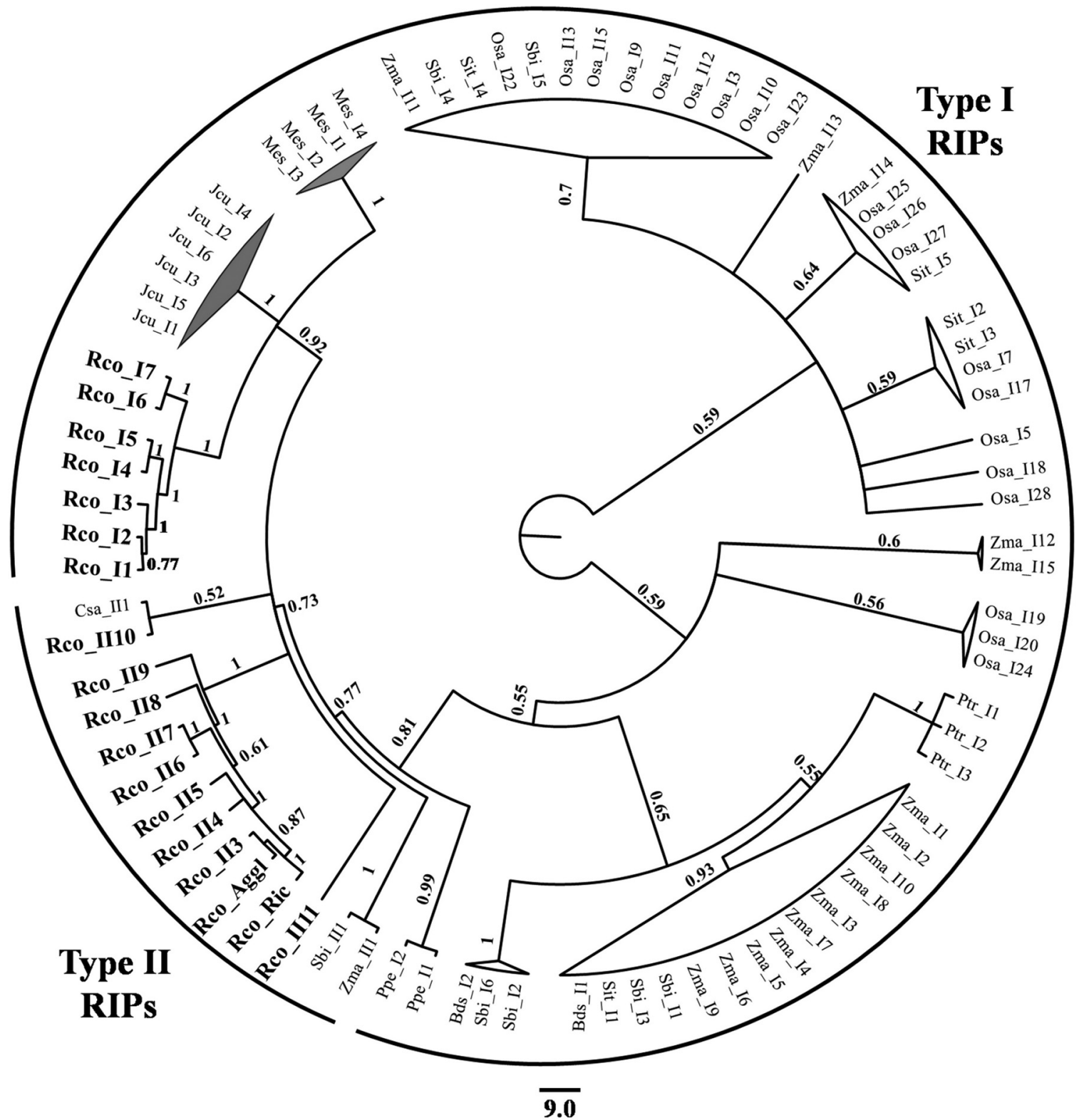

Figure 4 - Bayesian phylogenetic tree showing the evolutionary relationships among the R. communis (Rco), Manihot esculenta (Mes), Jatropha curcas (Jcu), Prunus persica (Ppe), Cucumis sativus (Csa), Populus trichocarpa (Ptr), Zea mays (Zma), Sorghum bicolor (Sbi), Setaria italic (Sit), Brachypodium distachyo (Bdi) and Oryza sativa (Osa) RIPs. The primary clustered monocot RIPs are shown by white sectors and Euphorbiaceae plants (with the exception of $R$. communis) are shown by gray sectors. The midpoint rooting and a priori posterior probability values are also shown. 


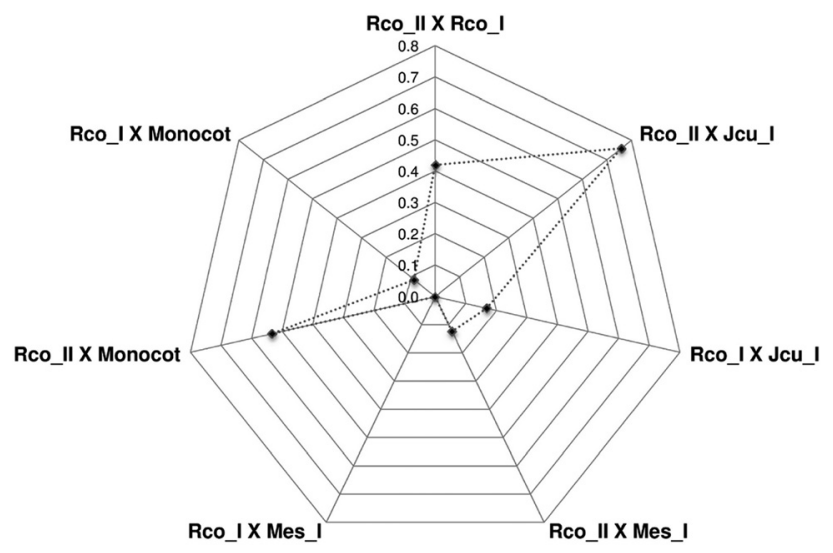

Figure 5 - Evolutionary functional divergence analysis of RIP genes showing the mean values of the divergence coefficient $(\theta)$ between the type I and II R. communis (Rco), M. esculenta (Mes), J. curcas (Jcu) or monocot RIPs. The divergence coefficient measures the site-specific evolutionary rate, where $\theta=0$ indicates no functional divergence and increasing values indicate increasing functional divergence, with $\theta=1$ being the maximum.
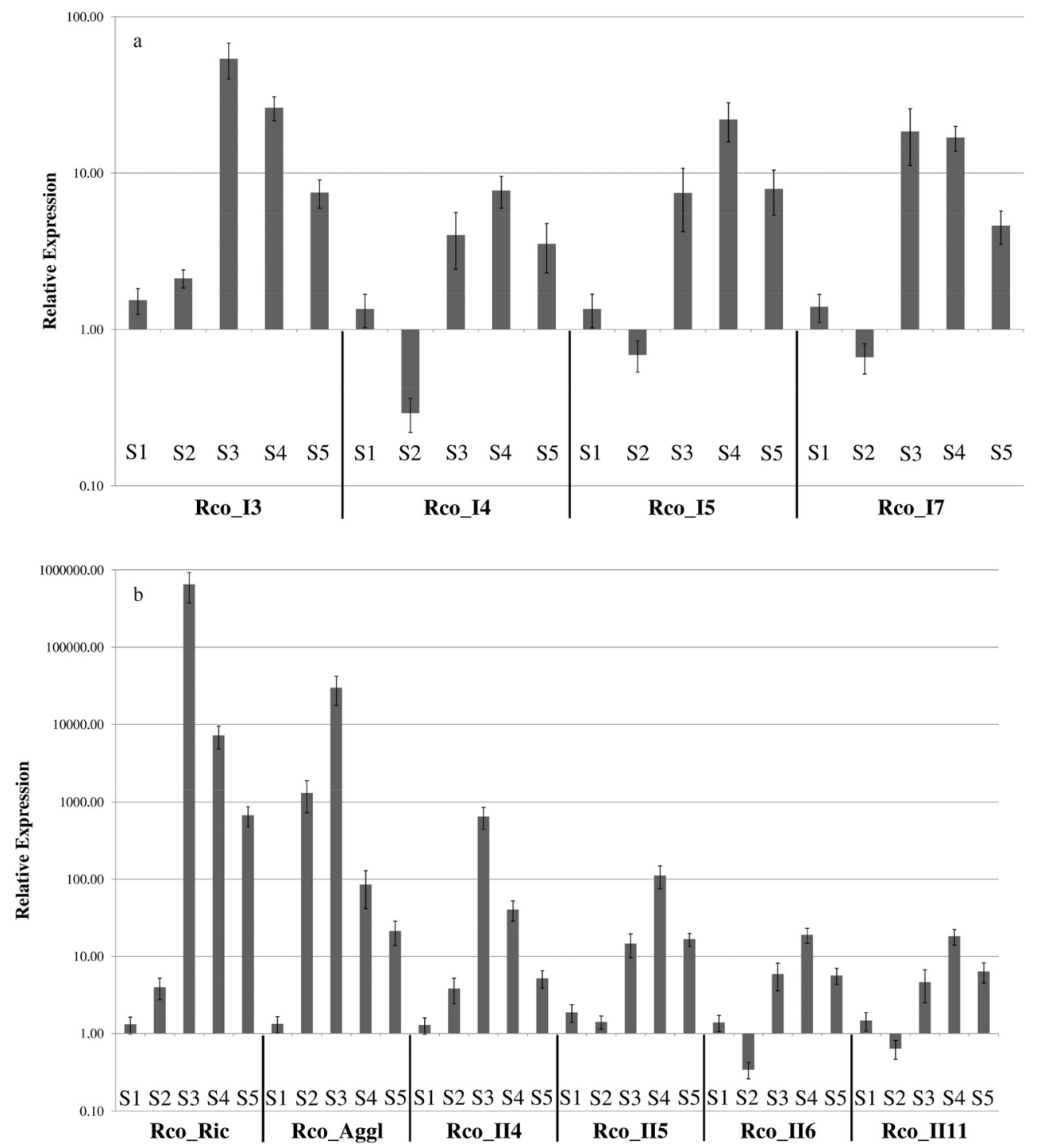

Figure 6 - Relative gene expression of $R$. communis RIPs as measured by RT-qPCR in the five stages of seed development. (A) The relative expression levels of Rco_I3, 4, 5 and 7. (B) The relative expression levels of Rco_Ric, Rco_Aggl and Rco_II 4, 5, 6 and 11. The expression data are shown on a logarithmic scale. The RIP gene expression levels were normalized at the S1 stage by the $2^{-\Delta \Lambda C t}$ method using the elongation factor B (29785.m000934), ubiquitin (30169.m006323) and ubiquitin conjugation protein rad6 (29736.m002026) genes. The bars represent the mean \pm standard deviations ( $\mathrm{n}=4$ ). 


\section{Discussion}

\section{Identification of plant RIPs}

A systematic search in the public Phytozome and NCBI databases resulted in the identification of 84 putative ribosome-inactivation proteins (RIPs), 18 of which occurred in castor bean. Of the 26 plant species deposited in the Phytozome database, only 10 contained RIPs and five of them were monocots. Although pectin methyl esterase has RIP activity in Arabidopsis (De-la-Pena et al., 2008) no RIP coding sequences were identified in the Arabidopsis genome.

Basal organisms, such as moss and chlorophytes, do not contain RIP genes. However, RIP activity has been identified in the fruiting bodies of the mushrooms Hypsizygus marmoreus (Wang et al., 2006), Volvariella volvacea (Yao et al., 1998), Pleurotus tuberregium (Wang and $\mathrm{Ng}, 2001$ ), Lyophyllum shimeji (Lam and $\mathrm{Ng}, 2001$ ) and Flammulina velutipes (Wang and $\mathrm{Ng}, 2001$ ) and in the brown algae Laminaria japonica (Liu et al., 2002). Unfortunately, genome sequences are presently unavailable for these organisms. Although Escherichia coli and Shigella dysenteriae contain RIPs, they were not included in our analysis because bacterial RIPs are evolutionarily distant from those of plants and their inclusion in this study could have led to a bias in the phylogenetic analysis.

At least 36 plant RIP genes have been characterized and their protein sequences are available (Girbes et al., 2004), although there is little information on the genome structure and organization for most of these species. Consequently, the abundance of type I and II RIPs cannot be assessed. For this reason, we focused on plant species for which a full genome was available. We identified 30 unpublished RIPs belonging to eight plant species; three of these genes were for type II RIPs, which are far less abundant than type I RIPs (Girbes et al., 2004). Moreover, the three new type II RIPs rom C. sativus, Z. mays and $S$. bicolor differed in their core active sites that are responsible for toxicity. Changes in the core active site residues of ricin are related to a decrease in toxicity (Day et al., 1996; Leshin et al., 2010). These three species have been subjected to genetic breeding ( $\mathrm{Li}$ et al., 2011; Tenaillon and Charcosset, 2011) that may have selected for plants that contain nontoxic RIPs. However, this hypothesis needs to be confirmed by examining the RIP genomic sequences from wild-type relatives of C. sativus, Z. mays and $S$. bicolor.

The recently published draft of the $R$. communis genome sequence revealed the existence of 28 members that were associated with the ricin/agglutinin gene family. These members included seven putative type II RIPs, nine putative type I RIPs, four putative pseudogenes and eight fragments of the B chain (Chan et al., 2010). In contrast, in the $R$. communis genome, our analysis identified seven type I and nine type II RIP genes, in addition to ricin and aggluti- nin. Our analysis also identified a previously characterized pseudogene (29988.m000128), referred to here as Rco_II5. Rco_II5 and Rco_II11 (60638.m00025) had gene lengths similar to type I RIPs but phylogenetic analyses showed that they were grouped with Rco_ric (ricin), Rco_Aggl (agglutinin) and other putative type II RIPs.

Chan et al. (2010) identified two cases in which adjacent ricin family members accumulated frame-shift mutations and could correspond to pseudogenes. Our phylogenetic analysis suggested that the recent duplication event that generated Rco_II4 and Rco_II5 introduced a guanine into the coding sequence and that this introduced a chain termination mutation by incorporating a stop codon; this mutation resulted in the formation of a truncated protein. The sequence downstream of the stop codon, which is characterized as intergenic, is actually a fragment of the A and B chains, and the upstream gene (29988.t000011) is a portion of the Rco_II5 B chain. However, we observed no B chain counterpart upstream of the Rco_II11 gene. This gene may have originated from an early duplication event that occurred within the type II RIP group, with the Rco_II11 B chain counterpart being lost during subsequent evolution.

The ricin B chain counterparts are lectins that recognize carbohydrate cellular receptors and mediate intracellular glycoprotein trafficking; this contributes to the greater toxicity of type II RIPs compared to type I RIPs (Dodd and Drickamer, 2001). The B chains of ricin and agglutinin contain four domains and amino acid substitutions could account for differences in toxicity between ricin and agglutinin (Roberts et al., 1985). Rco_II3 and Rco_II10 contain a shorter $\mathrm{B}$ chain than ricin and agglutinin because of the absence of 1-2 lectin domains, although the influence of this lack of B chain domains on the function of Rco_II3 and Rco_II10 remains unclear. Neither gene was expressed in any of the five seed stages analyzed, perhaps because Rco III and Rco III10 are pseudogenes. Rco III10 contains a greater number of introns than other castor bean RIPs. This finding supports the pseudogene hypothesis but requires confirmation.

\section{The evolution of plant RIPs}

General phylogenetic and evolutionary studies of RIPs have shown that the distribution of these proteins in plants and bacteria is the product of independent parallel duplications (Girbes et al., 2004; Jiang et al., 2008). In the present work, a robust phylogenetic analysis of plants for which the genomes have been sequenced confirmed that RIPs evolved in an independent, parallel manner.

Our phylogenetic analyses showed that the amino acid sequences of genes from members of the same RIP type are related. This finding suggests that the evolution of these proteins was based on the RIP type and not on the taxon, in contrast to previous proposals. For example, Girbes et al. (2004) proposed that all of the monocot type 1 
RIPs were related, a conclusion that resulted in the family Poaceae appearing as a homogeneous group. Jiang et al. (2008) subsequently showed that the $O$. sativa sequences were separated into subclades, a conclusion that supports our findings for $O$. sativa and other members of the Poaceae. Our phylogenetic analyses also showed that all type II monocot RIPs were clustered with type II eudicot RIPs, indicating that that Poaceae is indeed a heterogeneous group.

The A chains of all type II RIPs are related, which suggests that they have a common origin (Girbes et al., 2004). Our phylogenetic analyses showed that the separation between type I and II occurred before the monocot/eudicot split in the late Jurassic-early Cretaceous periods (140-150 million years ago) (Chaw et al., 2004).

With the exception of Rco_II10 and Rco_II11, the $R$. communis RIPs clustered into two main groups that corresponded to type I and II RIPs. Most of the $R$. communis RIPs are products of recent duplication events; however, Rco_Ric and Rco_Aggl have been suggested to be the products of an ancestral RIP gene duplication (Roberts et al., 1985). The phylogenetic tree shown in Figure 4 confirms that Rco_II3 is a product of an Rco_Aggl duplication. Rco Aggl, or agglutinin, is a dimeric protein and this conformational structure is related to its lower toxicity when compared to ricin (Olsnes, 2004). Rco_Aggl exists as a heterodimer in which the non-identical protein monomers differ in their surface charge and molecular mass (Hegde and Podder, 1998). Rco_II3 may also exist as a heterodimer but this remains to be confirmed experimentally.

Girbes et al. (2004) demonstrated that Iris hollandica type I RIP was phylogenetically related to I. hollandica type II RIPs, possibly because of a B chain deletion. A similar B chain deletion event clearly occurred with Rco_II5 (Figures 1,2 and 4) and may also have generated Rco_II11.

The functional divergence analysis between the Euphorbiaceae and monocots strongly corroborated our phylogenetic analyses, which showed that RIPs of the same type or class were less functionally divergent even when derived from different taxa. The lack of strong functional divergence between type I and type II $R$. communis RIPs may be indicative of their overlapping functions.

\section{Expression of $R$. communis RIPs during seed development}

PCR and DNA sequencing confirmed the presence of the 18 RIPs in the castor bean genome and the specificity of each primer. Expression of the Rco RIP gene was assessed qualitatively by RT-PCR based on the absence/presence of PCR amplicons in mature seed cDNA. Our findings agreed with previous studies showing that Rco_Ric and Rco_Aggl were expressed in $R$. communis seeds (Chen et al., 2005). Since Rco_Ric and Rco_Aggl show seed-specific expression in castor beans (Barnes et al., 2009) the current study focused primarily on RIP expression during five stages of seed developmental as assessed by RT-qPCR. Our results corroborated previous findings obtained by northern blotting (Tregear and Roberts, 1992), RT-PCR (Chen et al., 2005; Barnes et al., 2009), expressed sequence tags (Lu et al., 2007) and seed proteomics (Houston et al., 2009), all of which demonstrated that Rco_Ric and Rco_Aggl were expressed at higher levels in seeds that contain a fully expanded endosperm (S3-S5). Indeed, Rco_Ric and Rco_Aggl were the RIPs with the highest levels of expression in developing seeds, perhaps because these RIPs were the first to be discovered (Olsnes and Kozlov, 2001). Our results also provide the first evidence that four other type I and II $R$. communis RIPs are expressed in seeds, including Rco_II5, which was previously characterized as a pseudogene (Chan et al., 2010).

Jiang et al. (2008) analyzed the expression of $O$. sativa RIPs in seedlings and suggested that RIPs that were not expressed may have been pseudogenes. As shown here, eight castor bean RIPs showed no detectable expression during seed development. However, broader expression analyses that include different tissues, developmental stages and responses to biotic and abiotic stress, are required to determine whether these eight RIPs actually correspond to pseudogenes.

\section{The functions of castor bean RIPs}

Plant RIP genes were reported to be regulated by abiotic stress and senescence (Stirpe et al., 1996), salinity (Rippmann et al., 1997), drought (Bass et al., 2004) and oxidative stress (Iglesias et al., 2005, 2008), and by biotic stress, such as viral infections (Iglesias et al., 2005), insect herbivory (Zhou et al., 2000; Bertholdo-Vargas et al., 2009) and fungal infections ( $\mathrm{Xu}$ et al., 2007). RIP expression patterns can be modulated by plant hormones such as jasmonic acid (Reinbothe et al., 1994; Xu et al., 2007), abscisic acid (Xu et al., 2007), gibberellic acid (Ishizaki et al., 2002) and ethylene (Park et al., 2002).

Recently, Rco_Ric (ricin) was associated with the inhibition of seed predation (Barnes et al., 2009) and some RIPs have dual activities on superoxide dismutase (Sharma et al., 2004) and lipase (Morlon-Guyot et al., 2003). RIPs may initially have been related to pathogen defenses (Stirpe, 2004; Stirpe and Battelli, 2006). During the evolution of RIPs, one or more gene fusion events probably occurred among type I RIPs and the lectin genes that correspond to the B chain (Figure 7). These events may have resulted in the appearance of type II RIPs, which have greater toxicity and show greater inhibition of herbivory. Morlon-Guyot et al. (2003) demonstrated that in addition to its welldemonstrated toxicity, ricin also has lipolytic activity that could facilitate its translocation from the membrane to the cytosol. Recently, Leshin et al. (2010) analyzed the RIP activity of six type II $R$. communis RIPs that displayed toxicity but the lipolytic activity was not analyzed. The $R$. communis RIP genes have an expression pattern similar to 


\section{H1: Gene Fusion}

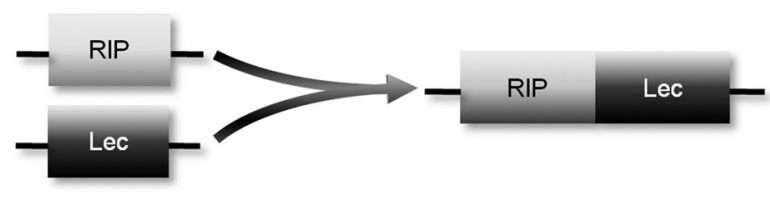

H2: Partial Duplication

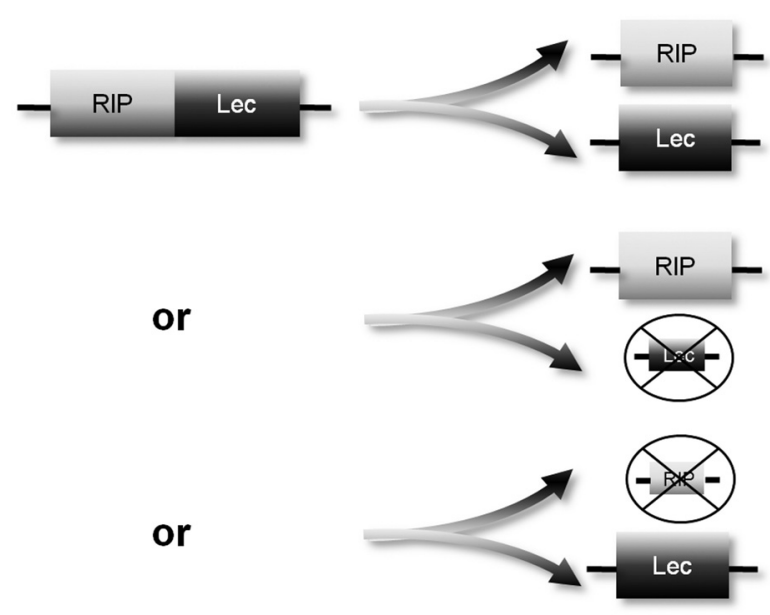

Figure 7 - Hypotheses to explain the appearance of type II RIPs and their putative return to the independent, separate domains of type I RIPs and lectins. (H1) Gene fusion: the result of gene duplication of an RIP gene and lectin gene is fusion leading to a type II RIP. (H2) Partial duplication: a type II RIP may be partially duplicated, with separation of the RIP and lectin genes or loss of the A or B chain.

that of genes involved in the castor bean triacylglycerol (TAG) biosynthesis pathway (Cagliari et al., 2010). We speculate that the lipolytic activity of ricin may be associated with TAG metabolism. Ricin gene knockdown or knockout protocols (Sujatha and Sailaja, 2005; Sailaja et al., 2008) may help to elucidate the role of RIPs in TAG metabolism.

In conclusion, we have identified 30 new RIPencoding genes from eight plant species, including three new type II RIPs in the castor bean RIP gene family. Expression analyses revealed that, in addition to ricin and agglutinin, eight RIPs are expressed during seed development. Phylogenetic analyses also showed that the type I and type II RIP gene divergence event most likely occurred before the separation of the monocots and eudicots.

\section{Acknowledgments}

This research was supported by grants from the Projeto Agroestruturante FINEP (Financiadora de Estudos e Projetos), Fundação de Amparo à Pesquisa do Estado do Rio Grande do Sul (FAPERGS) and Conselho Nacional de Desenvolvimento Científico e Tecnológico (CNPq). GLM and $\mathrm{AC}$ were supported by $\mathrm{PhD}$ fellowships from Coordenação de Aperfeiçoamento de Pessoal de Nivel Superior
(CAPES) and CNPq, respectively. ATZ, APK and FSM were supported by PNPD/CAPES fellowships, and MMP and RM were supported by CNPq research fellowships (grant nos. 308708/2006-7 and 307868/2011-7, respectively). The authors thank Dr. Sergio Delmar dos Anjos Silva (EMBRAPA-CPACT) for providing the castor bean Al-Guarany seeds.

\section{References}

Barnes DJ, Baldwin BS and Braasch DA (2009) Ricin accumulation and degradation during castor seed development and late germination. Ind Crop Prod 30:254-258.

Bass HW, Krawetz JE, Zinselmeier C, Habben JE and Boston RS (2004) Maize ribosome-inactivating proteins (RIPs) with distinct expression patterns have similar requirements for proenzyme activation. J Exp Bot 55:2219-2233.

Bertholdo-Vargas LR, Martins JN, Bordin D, Salvador M, Schafer AE, Barros NM, Barbieri L, Stirpe F and Carlini CR (2009) Type 1 ribosome-inactivating proteins entomotoxic, oxidative and genotoxic action on Anticarsia gemmatalis (Hubner) and Spodoptera frugiperda (J.E. Smith) (Lepidoptera, Noctuidae). J Insect Physiol 55:51-58.

Cagliari A, Margis-Pinheiro M, Loss G, Mastroberti AA, Mariath JEA and Margis R (2010) Identification and expression analysis of castor bean (Ricinus communis) genes encoding enzymes from the triacylglycerol biosynthesis pathway. Plant Sci 179:499-509.

Chan AP, Crabtree J, Zhao Q, Orvis LH, Puiu J, Melake-Berhan D, Jones A, Redman KM, Chen J, Cahoon G, et al. (2010) Draft genome sequence of the oilseed species Ricinus communis Nat Biotechnol 28:951-956.

Chaw SM, Chang CC, Chen HL and Li WH (2004) Dating the monocot-dicot divergence and the origin of core eudicots using whole chloroplast genomes. J Mol Evol 58:424-441.

Chen GQ, He XH, Liao LP and McKeon TA (2004) 2S albumin gene expression in castor plant (Ricinus communis $\mathrm{L}$ ). J Am Oil Chem Soc 81:867-872.

Chen GQ, He X and McKeon TA (2005) A simple and sensitive assay for distinguishing the expression of ricin and Ricinus communis agglutinin genes in developing castor seed $(R$ communis L). J Agric Food Chem 53:2358-2361.

Crooks GE, Hon G, Chandonia JM and Brenner SE (2004) WebLogo: A sequence logo generator Genome Res 14:1188-1190.

Day PJ, Ernst SR, Frankel AE, Monzingo AF, Pascal JM, Molina-Svinth MC and Robertus JD (1996) Structure and activity of an active site substitution of ricin A chain. Biochemistry 35:1098-11103.

De-la-Pena C, Badri DV and Vivanco JM (2008) Novel role for pectin methylesterase in Arabidopsis: A new function showing ribosome-inactivating protein (RIP) activity. Biochim Biophys Acta 1780:773-783.

Ding Y, Too H, Liu WZ, Bartlam Y, Dong M, Wong Y, Shaw K and Rao P (2003) The structural basis of Trp192 and the C-terminal region in trichosanthin for activity and conformational stability. Protein Eng 16:351-356.

Dodd RB and Drickamer K (2001) Lectin-like proteins in model organisms: Implications for evolution of carbohydratebinding activity. Glycobiology 11:71R-79R. 
Donayre Torres AJ, Esquivel Soto E, Gutierrez Xicotencatl MD, Esquivel Guadarrama FR and Gomez Lim MA (2009) Production and purification of immunologically active core protein p24 from HIV-1 fused to ricin toxin B subunit in E. coli. Virol J 6:e17.

Edgar RC (2004) MUSCLE: Multiple sequence alignment with high accuracy and high throughput. Nucleic Acids Res 32:1792-1797.

Endo Y, Gluck A and Wool IG (1991) Ribosomal RNA identity elements for ricin A-chain recognition and catalysis. J Mol Biol 221:193-207.

Endo Y and Tsurugi K (1987) RNA N-glycosidase activity of ricin A-chain. Mechanism of action of the toxic lectin ricin on eukaryotic ribosomes. J Biol Chem 262:8128-8130.

Franz DR, Jahrling PB, Friedlander AM, McClain DJ, Hoover DL, Bryne WR, Pavlin JA, Christopher GW and Eitzen Jr EM (1997) Clinical recognition and management of patients exposed to biological warfare agents. JAMA 278:399-411.

Frigerio L and Roberts LM (1998) The enemy within: Ricin and plant cells. J Exp Bot 49:1473-1480.

Frigerio L, Vitale A, Lord JM, Ceriotti A and Roberts LM (1998) Free ricin A chain proricin and native toxin have different cellular fates when expressed in tobacco protoplasts. J Biol Chem 273:14194-14199.

Frigerio L, Jolliffe NA, Di Cola A, Felipe DH, Paris N, Neuhaus JM, Lord JM, Ceriotti A and Roberts LM (2001) The internal propeptide of the ricin precursor carries a sequencespecific determinant for vacuolar sorting. Plant Physiol 126:167-175.

Girbes T, Ferreras JM, Arias FJ and Stirpe F (2004) Description distribution activity and phylogenetic relationship of ribosome-inactivating proteins in plants fungi and bacteria. Mini Rev Med Chem 4:461-476.

Gu X and Vander Velden K (2002) DIVERGE: Phylogeny-based analysis for functional-structural divergence of a protein family. Bioinformatics 18:500-501.

Guex N and Peitsch MC (1997) SWISS-MODEL and the SwissPdbViewer: An environment for comparative protein modeling. Electrophoresis 18:2714-2723

Guindon S, Dufayard JF, Lefort V, Anisimova M, Hordijk W and Gascuel O (2010) New algorithms and methods to estimate maximum-likelihood phylogenies: Assessing the performance of PhyML 30. Syst Biol 59:307-321.

Halling KC, Halling AC, Murray EE, Ladin BF, Houston LL and Weaver RF (1985) Genomic cloning and characterization of a ricin gene from Ricinus communis. Nucleic Acids Res 13:8019-8033.

Hegde R and Podder SK (1998) Evolution of tetrameric lectin Ricinus communis agglutinin from two variant groups of ricin toxin dimmers. Eur J Biochem 254:596-601.

Houston NL, Hajduch M and Thelen JJ (2009) Quantitative proteomics of seed filling in castor: Comparison with soybean and rapeseed reveals differences between photosynthetic and non-photosynthetic seed metabolism. Plant Physiol 151:857-868.

Iglesias R, Perez Y, de Torre C, Ferreras JM, Antolin P, Jimenez P, Rojo MA, Mendez E and Girbes T (2005) Molecular characterization and systemic induction of single-chain ribosome-inactivating proteins (RIPs) in sugar beet (Beta vulgaris) leaves. J Exp Bot 56:1675-1684.
Iglesias R, Pérez Y, Citores L, Ferreras JM, Méndez E and Girbés TJ (2008) Elicitor-dependent expression of the ribosomeinactivating protein beetin is developmentally regulated. $\mathrm{J}$ Exp Bot 59:121512-23.

Ishizaki T, Megumi C, Komai F, Masuda K and Oosawa K (2002) Accumulation of a $31-\mathrm{kDa}$ glycoprotein in association with the expression of embryogenic potential by spinach callus in culture. Physiol Plant 114:109-115.

Jiang SY, Ramamoorthy R, Bhalla R, Luan HF, Venkatesh PN, Cai M and Ramachandran S (2008) Genome-wide survey of the RIP domain family in Oryza sativa and their expression profiles under various abiotic and biotic stresses. Plant Mol Biol 67:603-614.

Kim Y, Mlsna D, Monzingo AF, Ready MP, Frankel A and Robertus JD (1992) Structure of a ricin mutant showing rescue of activity by a noncatalytic residue. Biochemistry 31:3294-3296.

Lam SK and Ng TB (2001) First simultaneous isolation of a ribosome inactivating protein and an antifungal protein from a mushroom (Lyophyllum shimeji) together with evidence for synergism of their antifungal effects. Arch Biochem Biophys 393:271-280.

Lamb FI, Roberts LM and Lord JM (1985) Nucleotide sequence of cloned cDNA coding for preproricin. Eur J Biochem 148:265-270.

Leshin J, Danielsen M, Credle JJ, Weeks A, O'Connell KP and Dretchen K (2010) Characterization of ricin toxin family members from Ricinus communis. Toxicon 55:658-661.

Li Y, Yang L, Pathak M, Li D, He X and Weng Y (2011) Fine genetic mapping of cp: A recessive gene for compact (dwarf) plant architecture in cucumber Cucumis sativus L. Theor Appl Genet 123:973-983.

Liu RS, Yang JH and Liu WY (2002) Isolation and enzymatic characterization of lamjapin the first ribosome-inactivating protein from cryptogamic algal plant (Laminaria japonica A). Eur J Biochem 269:4746-4752.

Livak KJ and Schmittgen TD (2001) Analysis of relative gene expression data using real-time quantitative PCR and the $2^{-\Delta \Delta C t}$ method. Methods 25:402-408.

Lord JM, Roberts LM and Robertus JD (1994) Ricin: Structure mode of action and some current applications. FASEB J 8:201-208.

Lu C, Wallis JG and Browse J (2007) An analysis of expressed sequence tags of developing castor endosperm using a fulllength cDNA library. BMC Plant Biol 7:e42.

Monzingo AF and Robertus JD (1992) X-ray analysis of substrate analogs in the ricin A-chain active site. J Mol Biol 227:1136-1145.

Morlon-Guyot J, Helmy M, Lombard-Frasca S, Pignol D, Pieroni $\mathrm{G}$ and Beaumelle B (2003) Identification of the ricin lipase site and implication in cytotoxicity. J Biol Chem 278:17006-17011.

Olsnes S (2004) The history of ricin abrin and related toxins. Toxicon 44:361-370.

Olsnes S and Kozlov JV (2001) Ricin. Toxicon 39:1723-1728.

Park SW, Lawrence CB, Linden JC and Vivanco JM (2002) Isolation and characterization of a novel ribosome-inactivating protein from root cultures of pokeweed and its mechanism of secretion from roots. Plant Physiol 130:164-178. 
Peumans WJ, Hao Q and Van Damme EJ (2001) Ribosomeinactivating proteins from plants: More than RNA N-glycosidases? FASEB J 15:1493-1506.

Quevillon E, Silventoinen V, Pillai S, Harte N, Mulder N, Apweiler R and Lopez R (2005) InterProScan: Protein domains identifier. Nucleic Acids Res 33:116-120.

Rambaldi D and Ciccarelli FD (2009) FancyGene: Dynamic visualization of gene structures and protein domain architectures on genomic loci. Bioinformatics 25:2281-2282.

Ready M, Wilson K, Piatak M and Robertus JD (1984) Ricin-like plant toxins are evolutionarily related to single-chain ribosome-inhibiting proteins from Phytolacca. J Biol Chem 259:15252-15256.

Reinbothe S, Reinbothe C, Lehmann J, Becker W, Apel K and Parthier B (1994) JIP60, a methyl jasmonate-induced ribosome-inactivating protein involved in plant stress reactions. Proc Natl Acad Sci USA 91:7012-7016.

Rippmann JF, Michalowski CB, Nelson DE and Bohnert HJ (1997) Induction of a ribosome-inactivating protein upon environmental stress. Plant Mol Biol 35:701-709.

Roberts LM, Lamb FI, Pappin DJ and Lord JM (1985) The primary sequence of Ricinus communis agglutinin. Comparison with ricin. J Biol Chem 260:15682-15686.

Roberts LM and Smith DC (2004) Ricin: The endoplasmic reticulum connection. Toxicon 44:469-472.

Ronquist F and Huelsenbeck JP (2003) MrBayes 3: Bayesian phylogenetic inference under mixed models. Bioinformatics 19:572-1574.

Rozen S and Skaletsky H (2000) Primer3 on the WWW for general users and for biologist programmers. Meth Mol Biol 132:365-386.

Sailaja M, Tarakeswari M and Sujatha M (2008) Stable genetic transformation of castor (Ricinus communis L) via particle gun-mediated gene transfer using embryo axes from mature seeds. Plant Cell Rep 27:1509-1519.

Scadden DT, Schenkein DP, Bernstein Z, Luskey B, Doweiko J, Tulpule A and Levine AM (1998) Immunotoxin combined with chemotherapy for patients with AIDS-related nonHodgkin's lymphoma. Cancer 83:2580-2587.

Schnell R, Katouzi AA, Linnartz C, Schoen G, Drillich S, Hansmann ML, Schiefer D, Barth S, Zangemeister-Wittke U, Stahel RA, et al. (1996) Potent anti-tumor effects of an anti-CD24 ricin A-chain immunotoxin in vitro and in a disseminated human Burkitt's lymphoma model in SCID mice. Int J Cancer 66:526-531.

Scholz V and da Silva JN (2008) Prospects and risks of the use of castor oil as a fuel. Biomass Bioenergy 32:95-100.

Sharma N, Park SW, Vepachedu R, Barbieri L, Ciani M, Stirpe F, Savary BJ and Vivanco JM (2004) Isolation and characterization of an RIP (ribosome-inactivating protein)-like protein from tobacco with dual enzymatic activity. Plant Physiol 134:171-181.

Spivak L and Hendrickson RG (2005) Ricin. Crit Care Clin 21:815-824.

Stirpe F (2004) Ribosome-inactivating proteins. Toxicon 44:371-383.

Stirpe F and Battelli MG (2006) Ribosome-inactivating proteins: Progress and problems. Cell Mol Life Sci 63:1850-1866.

Stirpe F, Barbieri L, Gorini P, Valbonesi P, Bolognesi A and Polito L (1996) Activities associated with the presence of ri- bosome-inactivating proteins increase in senescent and stressed leaves. FEBS Lett 382:309-312.

Sujatha M and Sailaja M (2005) Stable genetic transformation of castor (Ricinus communis L) via Agrobacterium tumefaciens-mediated gene transfer using embryo axes from mature seeds. Plant Cell Rep 23:803-810.

Tamura K, Peterson D, Peterson N, Stecher G, Nei M and Kumar S (2011) MEGA5: Molecular evolutionary genetics analysis using maximum likelihood evolutionary distance and maximum parsimony methods. Mol Biol Evol 28:2731-2739.

Tenaillon MI and Charcosset A (2011) A European perspective on maize history. C R Biol 334:221-228.

Tregear JW and Roberts LM (1992) The lectin gene family of Ricinus communis: Cloning of a functional ricin gene and three lectin pseudogenes. Plant Mol Biol 18:515-525.

Wang $\mathrm{H}$ and $\mathrm{Ng} \mathrm{TB}$ (2001) Isolation and characterization of velutin a novel low-molecular-weight ribosomeinactivating protein from winter mushroom (Flammulina velutipes) fruiting bodies. Life Sci 68:2151-2158.

Wang WX, Dong JY, Zhou SY, Li WL and Zhao Y (1998) Modification of ricin and its hepatotoxicity and activity against hepatocellular cancer in mice. World $\mathrm{J}$ Gastroenterol 4:307-310.

Wang BZ, Zou WG, Liu WY and Liu XY (2006) The lower cytotoxicity of cinnamomin (a type II RIP) is due to its B-chain. Arch Biochem Biophys 451:91-96.

Xu J, Wang H and Fan J (2007) Expression of a ribosomeinactivating protein gene in bitter melon is induced by Sphaerotheca fuliginea and abiotic stimuli. Biotechnol Lett 29:1605-1610.

Yao QZ, Yu MM, Ooi LS, Ng TB, Chang ST, Sun SS and Ooi VE (1998) Isolation and characterization of a type 1 ribosomeinactivating protein from fruiting bodies of the edible mushroom (Volvariella volvacea). J Agric Food Chem 46:788-792

Zhou X, Li XD, Yuan JZ, Tang ZH and Liu WY (2000) Toxicity of cinnamomin - A new type II ribosome-inactivating protein to bollworm and mosquito. Insect Biochem Mol Biol $30: 259-264$

\section{Internet Resources}

Phytozome database, http://www.phytozme.org.

\section{Supplementary Material}

The following material concerning this article is available online:

Table S1 - Description of Ribosome Inactivating Proteins (RIPs) data used for phylogenetics analysis.

Figure S1 - Maximum likelihood phylogenetic tree for plant RIPs.

Figure S2 - Agarose gel electrophoresis of the $R$. communis RIP PCR products.

This material is available as part of the online article at http://www.scielo.br/gmb.

\section{Associate Editor: Adriana S. Hemerly}

License information: This is an open-access article distributed under the terms of the Creative Commons Attribution License, which permits unrestricted use, distribution, and reproduction in any medium, provided the original work is properly cited. 
Supplemental Table 1: Systematic classification, access codes, acronyms and active sites of all Ribosome Inactivating Proteins (RIPs) used for phylogenetics analysis. The acronyms in bold indicated the 30 unpublished coding RIPs. The critical residues of the active site responsible for toxic proprieties are shown by upper case letters. Species with a completely sequenced genome are shown in bold.

\begin{tabular}{|c|c|c|c|c|c|}
\hline Class & Family & Species & Access code & Acronyms & $\begin{array}{c}\text { RIP Active } \\
\text { Site }\end{array}$ \\
\hline \multirow{18}{*}{\multicolumn{2}{|c|}{ Lauraceae }} & \multirow{11}{*}{ Cinnamoтum camphora } & AY039801.1 & Cca_II1 & EavR \\
\hline & & & AY039802.1 & Cca_II2 & EavR \\
\hline & & & AY039803.1 & Cca_II3 & EavR \\
\hline & & & $60629 . \mathrm{m} 00002$ & Rco_RicII & EaaR \\
\hline & & & 60637.m00004 & Rco_Aggl II & EaaR \\
\hline & & & 60638.m00019 & Rco_II3 & EaaR \\
\hline & & & 60638.m00018 & Rco_II4 & EavR \\
\hline & & & 29988.m000128 & Rco_II5 & EavR \\
\hline & & & 29988.m000125 & Rco_II6 & EavR \\
\hline & & & $60638 . \mathrm{m} 00023$ & Rco_II7 & EavR \\
\hline & & & 60637.m00006 & Rco_II8 & EaiR \\
\hline & & \multirow{7}{*}{ Ricinus communis } & 29791.m000533 & Rco_II9 & EaaR \\
\hline & & & 29942.m000749 & Rco_II10 & Eyfs \\
\hline & & & 60638.m00025 & Rco_II11 & EaaR \\
\hline & & & 29638.m000512 & Rco_I1 & EaaR \\
\hline & & & 29638.m000513 & Rco_I2 & EaaR \\
\hline & & & 60638.m00022 & Rco_I3 & EaaR \\
\hline & & & 28842.m000952 & Rco_I4 & EaaR \\
\hline \multirow{16}{*}{\multicolumn{2}{|c|}{ Euphorbiaceae }} & & $29852 \mathrm{~m} 001982$ & Rco_I5 & EaaR \\
\hline & & & 29942.m000748 & Rco_I6 & EaaR \\
\hline & & & $30113 \mathrm{~m} 001449$ & Rco_I7 & EaaR \\
\hline & & \multirow{5}{*}{ Manihot esculenta } & cassava4.1_029773.mg & Mes_I1 & EasR \\
\hline & & & cassava4.1_031745.mg & Mes_I2 & EasR \\
\hline & & & cassava4.1_022815.mg & Mes_I3 & EasR \\
\hline & & & cassava4.1_023613.mg & Mes_I4 & EasR \\
\hline & & & AY069946.1 & Jcu_I1 & EaaR \\
\hline & & \multirow{5}{*}{ Jatropha curcas } & FJ357424.1 & Jcu_I2 & EaaR \\
\hline & & & JF357910.1 & Jcu_I3 & EaaR \\
\hline & & & EU395775.1 & Jcu_I4 & EaaR \\
\hline & & & AF469003.1 & Jcu_I5 & EaaR \\
\hline & & & EU195892.1 & Jcu_I6 & EaaR \\
\hline & & \multirow{2}{*}{ Euphorbia serrata } & AF457875.1 & Ese_I1 & EaaR \\
\hline & & & AF457874.1 & Ese_I2 & EaaR \\
\hline & & Gelonium multiflorum & L12243.1 & Gmu_I1 & EaaR \\
\hline \multirow{8}{*}{\multicolumn{2}{|c|}{ Rosaceae }} & \multirow{2}{*}{ Prunus persica } & ppa009409m.g & Ppe_I1 & EaaR \\
\hline & & & ppa009637m.g & Ppe_I2 & Eaas \\
\hline & & Bryonia dioica & L42298.1 & Bdi_I1 & EsaR \\
\hline & & Cucumis figrei & AB045560.1 & Cfi_I1 & EaaR \\
\hline & & Gynostemma pentaphyllum & AY513740.1 & Gpe_I1 & EaaR \\
\hline & & Luffa acutangula & EF183475.1 & Lac_I1 & EasR \\
\hline & & & EF183475.1 & Lcy_I1 & EasR \\
\hline & & Luffa cylindrica & X62371.1 & Lcy_I2 & EasR \\
\hline \multirow{8}{*}{\multicolumn{2}{|c|}{ Cucurbitaceae }} & Trichosanthes cucumerina & AF055086.1 & Tcu_I1 & EaaR \\
\hline & & \multirow{6}{*}{ Trichosanthes kirilowii } & J05434.1 & Tki_I1 & EaaR \\
\hline & & & AY082349.2 & Tki_I2 & EaaR \\
\hline & & & AF367252.1 & Tki_I3 & EaaR \\
\hline & & & M34858.1 & Tki_I4 & EaaR \\
\hline & & & AB000666.1 & Tki_I5 & EaaR \\
\hline & & & AB426591.1 & Tki_I6 & EaaR \\
\hline & & Cucumis sativus & Cucsa.001340 & Csa_II1 & Esak \\
\hline
\end{tabular}




\begin{tabular}{|c|c|c|c|c|}
\hline & Dianthus caryophyllus & X59260.1 & Dca_I1 & EaaR \\
\hline & & AF219237.1 & Dch_I1 & EavR \\
\hline & Dianthus chinensis & AF219238.1 & Dch_I2 & EavR \\
\hline & & AF219236.1 & Dch_I3 & EavR \\
\hline & & X59256.1 & Sof_I1 & EaaR \\
\hline Caryophyllaceae & & HM028667.1 & Sof_I2 & EaaR \\
\hline & Saponaria officinalis & AM748700.1 & Sof_I3 & EvaR \\
\hline & & X15655.1 & Sof_I4 & EaaR \\
\hline & & DQ105519.1 & Sof_I5 & EaaR \\
\hline & & FJ860050.1 & Sme_I1 & EaaR \\
\hline & Stellarıa medıa & GQ870262.1 & Sme_I2 & EaaR \\
\hline & & EU008738.1 & Apu_II1 & EaaR \\
\hline & & EU008736.1 & Apu_II2 & EaaR \\
\hline & Abrus pulchellus & EU008737.1 & Apu_II3 & EaaR \\
\hline Fabaceae & & EU008735.1 & Apu_II4 & EaaR \\
\hline & & X55667.1 & Apr_II1 & EaaR \\
\hline & Abrus precatorius & AF190173.1 & Apr_III2 & EaaR \\
\hline & Viscum articulatum & EF620539.1 & Var_II1 & EaaR \\
\hline & & AY377896.1 & Val_II1 & EaaR \\
\hline & & AY377895.1 & Val_II2 & EaaR \\
\hline & & AY377894.1 & Val_II3 & EvaR \\
\hline Viscaceae & & AY377893.1 & Val_II4 & EaaR \\
\hline & Viscum album & AY377892.1 & Val_II5 & EaaR \\
\hline & & AY377891.1 & Val_II6 & EaaR \\
\hline & & AY377890.1 & Val_II7 & EaaR \\
\hline & & AF369961.1 & Val_II8 & EaaR \\
\hline & Momordica balsamina & Z12175.1 & Mba_I1 & EaaR \\
\hline & & X57682.1 & Mch_I1 & EaaR \\
\hline & & DQ643968.1 & Mch_I2 & EaaR \\
\hline & & AY817142.1 & Mch_I3 & EaaR \\
\hline Momordiceae & & AJ748278.1 & Mch_I4 & EaaR \\
\hline & Momordica charantia & AF284811.1 & Mch_I5 & EaaR \\
\hline & & AY523412.1 & Mch_I6 & EaaR \\
\hline & & S79450.1 & Mch_I7 & EaaR \\
\hline & & DQ643967.1 & Mch_I8 & EaaR \\
\hline & & AB070925.1 & Sol_In & EaaR \\
\hline & spınacıa oleraceae & AB362336.1 & Sol_I2 & EaaR \\
\hline & & U85255.1 & Avi_-I1 & EaaR \\
\hline & Amaranthus viridis & AF004389.1 & Avi_I2 & EaaR \\
\hline & & U70215.1 & Avi_I3 & EaaR \\
\hline & Atriplex patens & DQ991968.1 & Apa_I1 & EaaR \\
\hline Amaranthaceae & & AM265609.1 & Bvu_I1 & EaaR \\
\hline & & AM265610.1 & Bvu_I2 & EaaR \\
\hline & Beta vulgaris & AM900411.1 & Bvu_I3 & EaaR \\
\hline & & X85967.1 & Bvu_I4 & EaaR \\
\hline & & AF228508.1 & Cal_I1 & EaaR \\
\hline & Chenopodium album & AF230812.1 & Cal_I2 & EaaR \\
\hline Nyctogingсеое & Bougainvillea spectabilis & DQ989495.1 & Bsp_I1 & EaaR \\
\hline Nyctaginaceae & Bougainvillea X buttiana & DQ013264.2 & Bbu_I1 & EaaR \\
\hline Araliaceae & Panax ginseng & DQ683359.1 & Pgi_III & EaaR \\
\hline Aizoaceae & Mesembryanthemum crystallinum & AF012899.1 & Mcr_I1 & EaaR \\
\hline & & AF249280.1 & Sni_III & EaaR \\
\hline & & U41299.1 & Sni_II2 & EaaR \\
\hline & & $\mathrm{U} 27122.1$ & Sni_II3 & EaaR \\
\hline Adoxaceae & Sambucus nigra & U76524.1 & Sni_II4 & EaaR \\
\hline & & U58358.1 & Sni_II5 & EaaR \\
\hline & & U58357.1 & Sni_II6 & EaaR \\
\hline & & U66191.1 & Sni_II7 & EaaR \\
\hline
\end{tabular}


Theaceae

Phytolaccaceae

Salicaceae

Poaceae

Monocots

The

(1)

GU951534.1

Camellia sinensis

Phytolacca americana

Sorghum bicolor

Brachypodium distachyon

Setaria italica

Phytolacca acinosa

Phytolacca heterotepala

Phytolacca insularis

Zea mays

Populus trichocarpa

.

Sorghum bicolor

Brachypodium distachyon




\begin{tabular}{|c|c|c|c|c|}
\hline & & LOC_Os07g09070 & Osa_I17 & EavR \\
\hline & Oryza sativa & LOC_Os07g37090 & Osa_I18 & EalR \\
\hline & & LOC_Os08g03820 & Osa_I19 & EsiR \\
\hline & & LOC_Os08g03900 & Osa_I20 & EpIR \\
\hline & & LOC_Os10g24050 & Osa_I22 & EalK \\
\hline & & LOC_Os10g42060 & Osa_I23 & EaaR \\
\hline & & LOC_Os11g01290 & Osa_I24 & EtqR \\
\hline & & LOC_Os11g06460 & Osa_I25 & EsaR \\
\hline & & LOC_Os11g06490 & Osa_I26 & EsaR \\
\hline & & LOC_Os11g06630 & Osa_I27 & EgaR \\
\hline & & LOC_Os11g38340 & Osa_I28 & EaaR \\
\hline & & FJ028816.1 & Hvu_I1 & EatR \\
\hline & Hordeum vulgare & M62905.1 & Hvu_I2 & EatR \\
\hline & & X66376.1 & Hvu_III & EaaR \\
\hline & & AF213984.1 & Pmu_II1 & EaaR \\
\hline Asparegaceae & Polygonatum multiflorum & AF213983.1 & Pmu_II2 & EaaR \\
\hline & & AF289116.1 & Mar_I1 & EaaR \\
\hline & & AF289120.1 & Mar_I2 & EaaR \\
\hline Hyacinthaceae & Muscari armeniacum & AF289118.1 & Mar_I3 & EatR \\
\hline & & AF289119.1 & Mar_I4 & EaaR \\
\hline & & AF289117.1 & Mar_I5 & EatR \\
\hline & & U78041.1 & Iho_I1 & Etar \\
\hline & & U78040.1 & Iho_I2 & Etar \\
\hline Iridaceae & Iris hollandica & U78039.1 & Iho_I3 & Etar \\
\hline & & AF256085.1 & Iho_III & EaaR \\
\hline
\end{tabular}




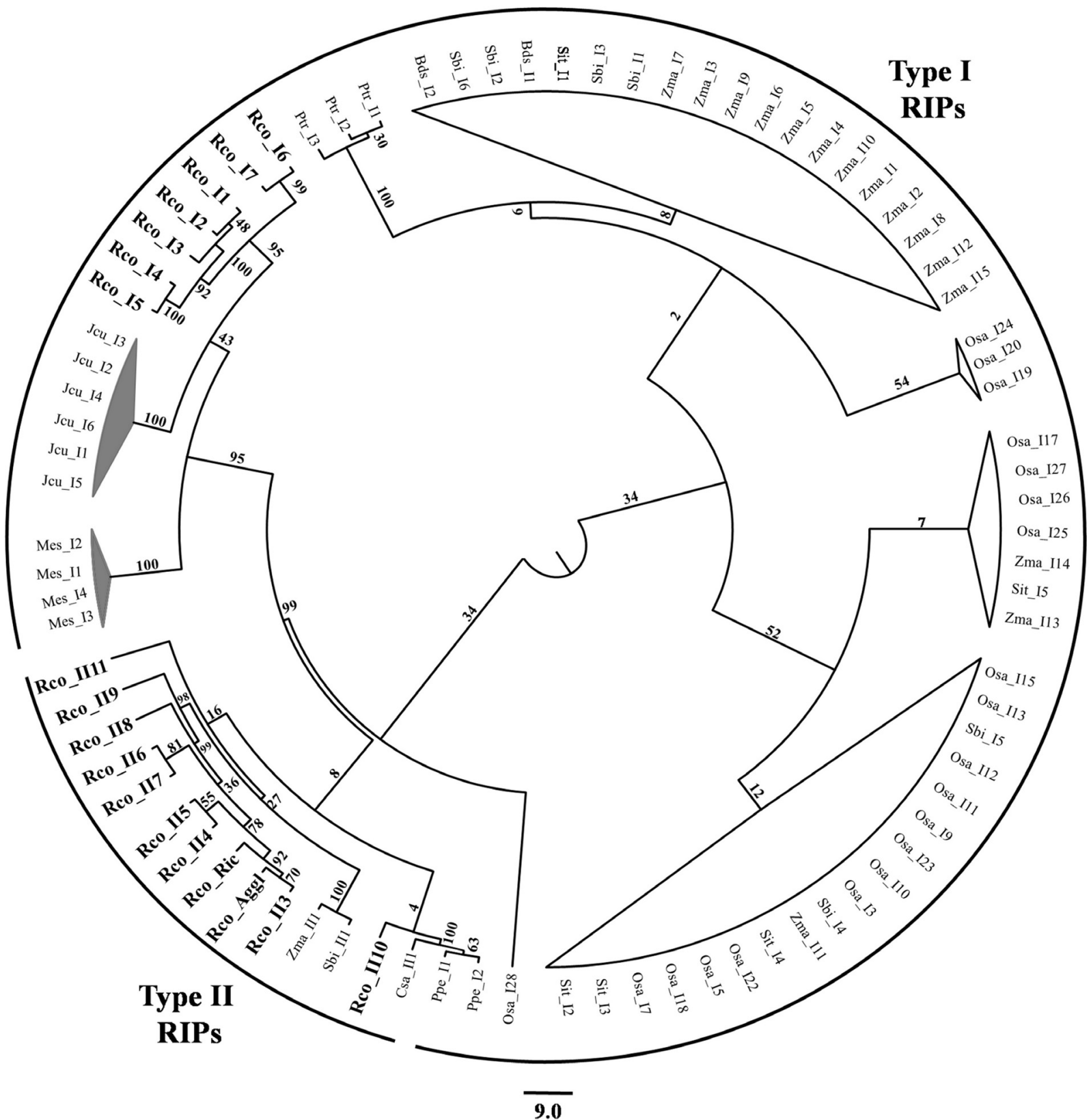

Figure S1 - Maximum likelihood phylogenetic tree showing the evolutionary relationships among the Brachypodium distachyo (Bdi), Cucumis sativus (Csa), Jatropha curcas (Jcu), Manihot esculenta (Mes), Oryza sativa (Osa), Populus trichocarpa (Ptr), Prunus persica (Ppe), R. communis (Rco), Setaria italic (Sit), Sorghum bicolor (Sbi) and Zea mays (Zma) RIPs. The primary clustered monocot RIPs are shown as white sectors, the RIPs corresponding to a Euphorbiaceae clade are indicated as gray sectors and the RIPs from $R$. communis clades are indicated in bold characters. The midpoint root and bootstrap values are also indicated. 


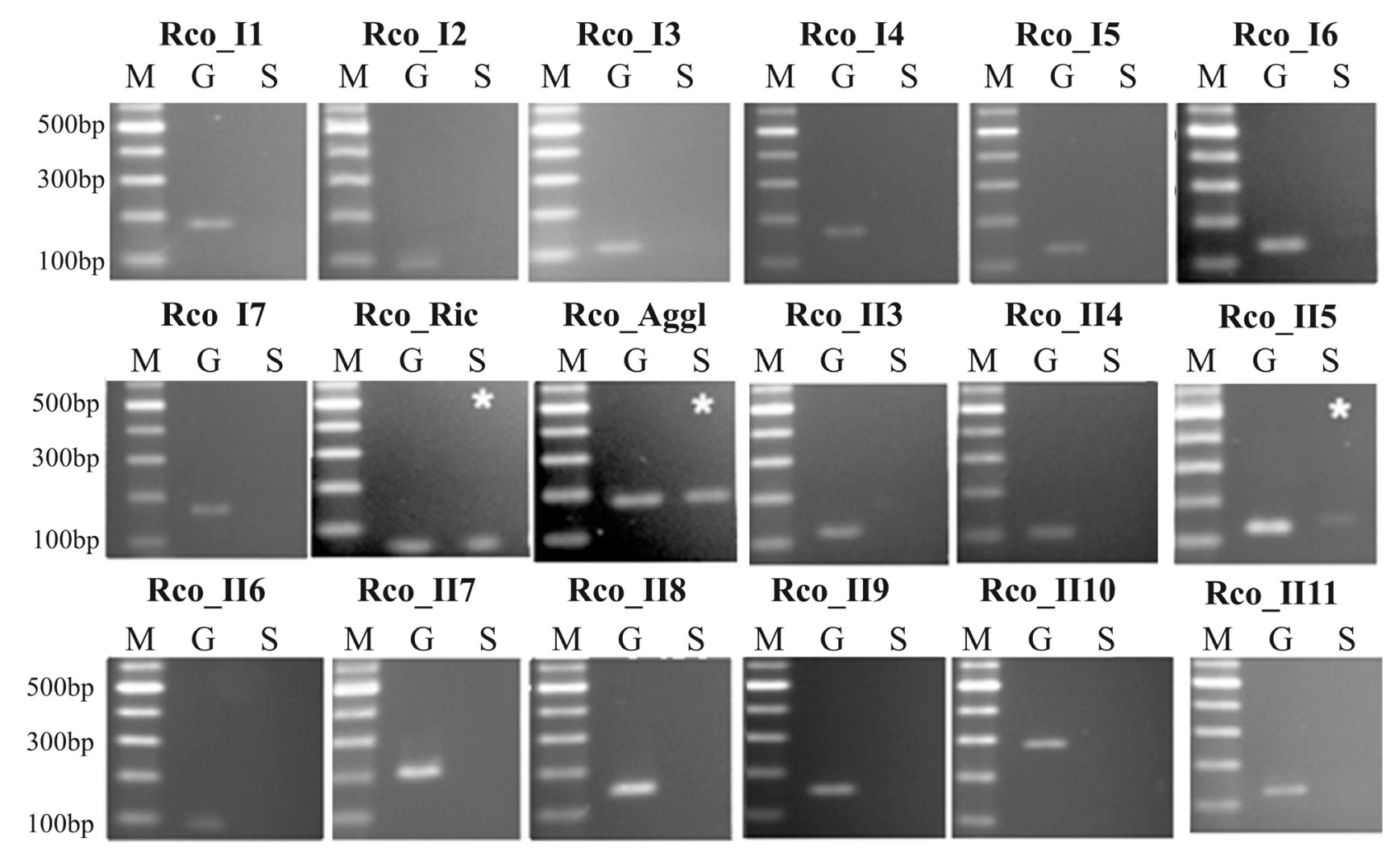

Figure S2 - Agarose gel electrophoresis of the $R$. communis RIP PCR products. PCR was done with genomic DNA (indicated by G) or with the cDNA of mature seeds (S5 stage; indicated by S). M - 100 bp ladder. The asterisks indicate the seed-specific cDNAs for which amplification was detected. 